\title{
Risk Factors Associated with Various Subtypes of Ischemic Stroke: A Prospective Study in BSMMU, Dhaka, Bangladesh
}

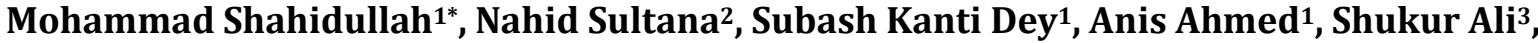 \\ Md. Raknuzzaman ${ }^{4}$ \\ ${ }^{1}$ Department of Neurology, Bangabandhu Sheikh Mujib Medical University (BSMMU), Dhaka, Bangladesh \\ ${ }^{2}$ Department of Community Medicine, Dhaka National Medical College, Dhaka, Bangladesh \\ ${ }^{3}$ Department of English, University of Development Alternative (UODA), Dhaka, Bangladesh \\ ${ }^{4}$ National Institute of Neurosciences \& Hospital, Dhaka, Bangladesh \\ Email: *sabuj23@gmail.com
}

How to cite this paper: Shahidullah, M., Sultana, N., Dey, S.K., Ahmed, A., Ali, S. and Raknuzzaman, Md. (2021) Risk Factors Associated with Various Subtypes of Ischemic Stroke: A Prospective Study in BSMMU, Dhaka, Bangladesh. Neuroscience \& Medicine, 12, 114-125.

https://doi.org/10.4236/nm.2021.124010

Received: August 6, 2021

Accepted: December 10, 2021

Published: December 13, 2021

Copyright $\odot 2021$ by author(s) and Scientific Research Publishing Inc. This work is licensed under the Creative Commons Attribution International License (CC BY 4.0).

http://creativecommons.org/licenses/by/4.0/

\begin{abstract}
Introduction: Stroke is the main cause of adult disability and the second most leading cause of death worldwide. The number of deaths due to stroke is 5.54 million worldwide. Globally, $70 \%$ of strokes and $87 \%$ of both stroke-related deaths and disability-adjusted life years occur in low and middle-income countries. Method: This was a prospective observational cross-sectional study conducted at Indoor, Outdoor, Stroke and Neuro-Intervention clinic of the Department of Neurology, Bangabandhu Sheikh Mujib Medical University Hospital (BSMMU), Dhaka, Bangladesh, from June-2019 to May-2020. A total of 220 ischemic stroke patients aged above 30 years confirmed by CT scan/MRI of brain. Data were collected with a pre-structured questionnaire from the patients, investigations reports and face-to-face interviews and analyzed using IBM SPSS software version 23.0. Proper consent was taken from the participants. The collected data were ANNOVA tests and association within the risk factors and the patterns of subtypes of ischemic stroke where $\mathrm{P}<0.05$ considered significant. Results: Among the 220 stroke patients, large-artery atherosclerosis (LAA), cardio-embolism (CE), small-vessel occlusion (SVO, stroke of other determined etiology (SODE) and stroke of undetermined etiology (SUDE) were being observed 84 (38.18\%), 14 (6.36\%), 63 (28.64\%), $12(5.45 \%)$ and 47 (18.18\%). Eighty-Six (39.09\%) prevalence of subtypes was found in rural areas whereas $134(60.91 \%)$ were in urban areas. The significant risk factors are associated with the prevalence of various subtypes $(\mathrm{p}<0.05)$. Conclusion: This study prevails the people of Bangladesh are vulnerable to various subtypes of ischemic stroke. The higher prevalence of large-artery atherosclerosis (LAA) in our patients suggests the presence of
\end{abstract}


uncontrolled hypertension, diabetes mellitus, smoking habit and dyslipidemia.

\section{Keywords}

Risk Factors, Associated, Various Subtypes, Ischemic Stroke, TOAST Criteria, Relationships, Etiology

\section{Introduction}

Stroke is the main cause of adult disability and the second most leading cause of death worldwide [1]. The number of deaths due to stroke is 5.54 million worldwide [2]. Stroke is also a major cause of long-term disability [3]. Globally, 70\% of strokes and $87 \%$ of both stroke-related deaths and disability-adjusted life years occur in low and middle-income countries [4]. The incidence of stroke varies among various countries. Over the last four decades, the stroke incidence in low and middle-income countries has become more than doubled. During these decades stroke incidence has declined by $42 \%$ in high-income countries [4]. In 2003-2005 the prevalence of stroke in India was 545/100,000 population [5]. Stroke is the third leading cause of death in Bangladesh [6], and the prevalence of stroke above the age of 40 is $370 / 100,000$ [7]. Of these $61 \%-80 \%$ is ischemic stroke and mortality due to stroke increased from 6\% to around $9 \%$ from 2006 to 2011 [6]. Stroke is defined by World Health Organization (WHO) as rapidly developing clinical signs of focal or global disturbance of cerebral function, with symptoms lasting 24 hours or longer or leading to death, with no apparent cause other than of non-traumatic vascular origin [8]. American heart association recently proposed a new definition of CNS infarction as brain, spinal cord, or retinal cell death due to ischemia, based on: pathological, imaging, or other objective evidence of cerebral, spinal cord, or retinal focal ischemic injury in a defined vascular distribution or clinical evidence of cerebral, spinal cord, or retinal focal ischemic injury based on symptoms persisting $>24$ hours or until death, and other etiologies excluded. Ischemic stroke was defined as an episode of neurological dysfunction caused by focal cerebral, spinal or retinal infarction [9]. Early treatment options of acute ischemic stroke are limited to revascularization, but only a few patients received this treatment owing to restrictions in terms of application time and indications [10]. Thus, primary prevention remains the most important general strategy for reducing the impact of stroke. The aetiopathogenesis of stroke is multifactorial, with multiple modifiable and nonmodifiable risk factors being associated. Nonmodifiable risk factors for stroke include older age, male gender, ethnicity, family history, and prior history of stroke. Modifiable risk factors include arterial hypertension, DM, dyslipidemia, cardiac disease, and carotid artery disease. Lifestyle factors include lack of physical activity, cigarette smoking, alcohol abuse and illicit drug use. Findings from the inter stroke study suggest that hypertension, current smoking, high waist-to-hip ratio, sedentary 
lifestyle, diabetes mellitus, alcohol intake, psychosocial stress and depression, cardiac causes and ratio of apolipoproteins B to A1 account for about $90 \%$ risk of stroke [11]. In a recent case-control study, hypertension, current smoking, abdominal obesity, diet and physical activity accounted for more than $80 \%$ of the global risk of stroke [11]. In 3 years, hospital-based study on risk factors of Ischemic stroke subtypes according to TOAST criteria, New Delhi, India revealed age, hypertension, diabetes, smoking, dyslipidemea, coronary artery disease (CAD), transient ischemic attack, the history of atrial fibrillation are the most important risk factors in Indian populations [12]. Lifestyle changes are likely to influence risk factor prevalence, which in turn may modify the stroke risk [13]. There are a number of ways in which ischemic strokes can occur, and the various etiologies often result in different clinical presentations and characteristic appearance of the lesion on imaging. Large hemispheric infarcts, usually resulting from occlusion of the internal carotid artery or proximal middle cerebral artery, had the worst prognosis [14]. Mortality was higher among patients with large-artery atherosclerotic lesions than among patients with lacunes [15]. Recurrent strokes are more likely among patients with cardioembolic stroke than among patients with stroke of other causes [16]. Carotid stenting and carotid endarterectomy are of proven usefulness in preventing recurrent stroke in patients with large-artery stenosis, and, aspirin and ticlopidine in patients with small-artery occlusive disease or lesser degrees of large-artery stenosis [17]. Anticoagulants or even cardiac surgery may be prescribed to prevent recurrent cardio-embolic stroke [18]. In this way, determining the cause of stroke does influence choices for management. The etiologies of ischemic stroke are diverse, making it difficult to include all stroke subtypes within a single classification system [19]. However, there are limited data and very few studies on patterns of subtype's ischemic strokes and their risks factors in our country. So, we purposively designed this study. The aim of this study is to investigate the risks factors associated with the patterns of subtypes of ischemic stroke according to TOAST criteria.

\section{Objectives}

General objective: To determine the risk factors associated with various subtypes of ischemic Stroke according to TOAST criteria.

\section{Specific objectives:}

- To analyze the risk factors in various subtypes of ischemic stroke.

- To find out the risk factors of ischemic stroke.

- To explore the relationships between ischemic stroke subtypes and risk factors.

\section{Methods}

This was a prospective observational cross-sectional study conducted at Indoor, Outdoor and Stroke and Neuro-Intervention clinic of the Department of Neurology, Bangabandhu Sheikh Mujib Medical University Hospital (BSMMU), 
Dhaka, Bangladesh, during June-2019 to May-2020. The ethical clearance of this study was taken from the Institutional Review Board (IRB) and a total of 220 ischemic stroke patients aged above 30 years confirmed by CT scan/MRI of brain were included in this study. Informed written consent was taken from each patient or his/her attendant for patients who were severely ill or unconscious. A complete history was taken regarding hypertension, diabetes, dyslipidemia, ischemic heart disease, current smoking history/O previous stroke, positive familial history, coronary artery diseases, alcohol consumption and demographic characteristics were noted in the questionnaire. The definition of stroke sub types is adapted from TOAST CRITERIA (trial of org 10172). Ischemic stroke was classified according to TOAST criteria. Data were collected with a prestructured questionnaire from the patients' investigations reports and face-toface interviews with the researcher (an expert neurologist). The collected data were analyzed using IBM SPSS software version 23.0. ANNOVA tests were done to investigate the association within the risk factors and the patterns of subtypes of ischemic stroke where $\mathrm{P}<0.05$ was considered significant. Multinomial logistic regression was done to investigate the individual risk factor responsible for the prevalence of subtypes of ischemic stroke comparably others risk factors. The inclusion and exclusion criteria were following:

\section{Inclusion criteria:}

- Patient diagnosed as first attack of ischemic stroke.

- Age $>30$ Years.

\section{Exclusion criteria:}

- Patient with previous history and evidence of stroke.

- Patient with hemorrhagic stroke, venous stroke.

- Patient or patient's guardian for severely ill or unconscious patient unwillingness to participate.

Table 1 shows the demographic characteristics and prevalence of subtypes of ischemic stroke among the studied patients. The highest prevalence of subtypes $70(31.82 \%)$ was found in the age group (51 - 60), of them LAA, CE, SVO, SODE and SUDE were being 36 (16.36\%), 01 (0.45\%), 17 (7.73\%), $02(0.91 \%)$, and14 $(6.36 \%)$. The age group (61 - 70) followed $58(26.36 \%)$ of prevalence of subtypes of ischemic stroke which was the second highest of them LAA, CE, SVO, SODE and SUDE were being, 23 (10.45\%), 02 (0.91\%), 18 (8.18\%), $01(0.45 \%)$ and 14 $(6.36 \%)$. Then the age group $(41-50)$ followed the prevalence of subtypes 47 $(21.36 \%)$, which was third in position of them, LAA, CE, SVO, SODE and SUDE were being, 14 (6.36\%), 06 (2.73\%), 20 (9.09\%), 01 (1.45\%) and 06 (2.73\%). The age group (31 - 40) followed $16(7.27 \%)$ of them, LAA, CE, SVO, SODE and SUDE were being, 02 (0.91\%), 02 (0.91\%), 03 (1.36\%), 05 (2.27\%) and 04 (1.82\%). The age group $>70$ followed $21(9.55 \%)$ prevalence of subtypes of them, LAA, CE, SVO, SODE and SUDE were being, 08 (3.64\%), 01 (0.45\%), 05 (2.27\%), 00\%, and $07(3.18 \%)$ whereas the age group $<30$ followed only $08(3.36 \%)$ prevalence of subtypes of them, LAA, CE, SVO, SODE and SUDE were being, 01 (0.45\%), 02 (0.91\%), 00\%, 03 (1.36\%), 02 (0.91\%). Among the studied patients, the prevalence 
Table 1. Baseline characteristics and the prevalence of subtypes of ischemicstrokes $(n=220)$.

\begin{tabular}{|c|c|c|c|c|c|c|c|}
\hline Age (Years): & $\begin{array}{c}\text { LLA } \\
\text { N (\%) }\end{array}$ & $\begin{array}{c}\mathrm{CE} \\
\mathrm{N}(\%)\end{array}$ & $\begin{array}{c}\text { SVO } \\
\text { N (\%) }\end{array}$ & $\begin{array}{l}\text { SODE } \\
\mathrm{N}(\%)\end{array}$ & $\begin{array}{l}\text { SUDE } \\
\text { N (\%) }\end{array}$ & Total (N\%) & P-value \\
\hline$<30$ & $01(0.45 \%)$ & $02(0.91 \%)$ & $00 \%$ & $03(1.36 \%)$ & $02(0.91 \%)$ & $08(3.36 \%)$ & \multirow{7}{*}{0.048} \\
\hline $31-40$ & $02(0.91 \%)$ & $02(0.91 \%)$ & $03(1.36 \%)$ & $05(2.27 \%)$ & $04(1.82 \%)$ & $16(7.27 \%)$ & \\
\hline $41-50$ & $14(6.36 \%)$ & $06(2.73 \%)$ & 20 (9.09\%) & $01(1.45 \%)$ & $06(2.73 \%)$ & 47 (21.36\%) & \\
\hline $51-60$ & $36(16.36 \%)$ & $01(0.45 \%)$ & 17 (7.73\%) & $02(0.91 \%)$ & $14(6.36 \%)$ & $70(31.82 \%)$ & \\
\hline $61-70$ & $23(10.45 \%)$ & $02(0.91 \%)$ & $18(8.18 \%)$ & $01(0.45 \%)$ & $14(6.36 \%)$ & $58(26.36 \%)$ & \\
\hline$>70$ & $08(3.64 \%)$ & $01(0.45 \%)$ & $05(2.27 \%)$ & $00 \%$ & 07 (3.18\%) & $21(9.55 \%)$ & \\
\hline Total & $84(38.18 \%)$ & $14(6.36 \%)$ & $63(28.64 \%)$ & $12(5.45 \%)$ & $47(21.36 \%)$ & $220(100 \%)$ & \\
\hline \multicolumn{7}{|l|}{ Sex: } & \multirow{4}{*}{0.001} \\
\hline Male: & $60(27.27 \%)$ & $03(1.36 \%)$ & $44(20.00 \%)$ & $44(20.00 \%)$ & $44(20.00 \%)$ & $150(68.18 \%)$ & \\
\hline Female: & $24(10.19 \%)$ & $11(5.00 \%)$ & $19(8.64 \%)$ & $05(2.27 \%)$ & $11(5.00 \%)$ & 70 (31.82\%) & \\
\hline Total & $84(38.18 \%)$ & $14(6.36 \%)$ & $63(28.64 \%)$ & $12(5.45 \%)$ & $47(21.36 \%)$ & $220(100 \%)$ & \\
\hline \multicolumn{7}{|l|}{ Religion: } & \multirow{4}{*}{0.001} \\
\hline Muslim & $78(35.45 \%)$ & $14(6.36 \%)$ & $60(27.27 \%)$ & $12(5.45 \%)$ & $46(20.91 \%)$ & $210(95.45 \%)$ & \\
\hline Hindus & $06(2.73 \%)$ & $00 \%$ & $03(1.36 \%)$ & $00 \%$ & $01(0.45 \%)$ & $10(4.55 \%)$ & \\
\hline Total & $84(38.18 \%)$ & $14(6.36 \%)$ & $63(28.64 \%)$ & $12(5.45 \%)$ & 47 (21.36\%) & $220(100 \%)$ & \\
\hline \multicolumn{7}{|l|}{ Residence: } & \multirow{4}{*}{0.001} \\
\hline Rural & $31(14.09 \%)$ & $06(2.73 \%)$ & $22(10.00 \%)$ & $05(2.27 \%)$ & $22(10.00 \%)$ & $86(39.09 \%)$ & \\
\hline Urban & $53(24.09 \%)$ & $08(3.64 \%)$ & $41(18.64 \%)$ & 07 (3.18\%) & $25(11.35 \%)$ & $134(60.91 \%)$ & \\
\hline Total & $84(38.18 \%)$ & $14(6.36 \%)$ & $63(28.64 \%)$ & $12(5.45 \%)$ & $47(21.36 \%)$ & $220(100 \%)$ & \\
\hline
\end{tabular}

of subtypes was found 150 (68.18\%) in male and 70 (31.82\%) in female. Among the patients, $86(39.09 \%)$ prevalence of subtypes was found who were from rural areas whereas 134 (60.91\%) was observed in urban areas.

Table 2 shows the overall prevalence of subtypes of ischemic strokes among the studied patients. Among the 220 stroke patients, Large-artery atherosclerosis (LAA), Cardio-embolism (CE), Small-vessel occlusion (SVO, Stroke of other determined etiology (SODE) and Stroke of undetermined etiology (SUDE) were being observed 84 (38.18\%), 14 (6.36\%), 63 (28.64\%), 12 (5.45\%) and 47 (18.18\%).

Table 3 shows 152 (69.09\%) stroke patients had Hypertension which was the highest risk factor associated with subtypes of ischemic stroke, of them, LAA, CE, SVO, SODE and SUDE were being observed 61 (72.62\%), 42 (66.67\%), 42 (66.67\%), $4(33.33 \%)$ and $36(76.60 \%)(\mathrm{P}=0.000) .98(44.55 \%)$ stroke patients had Diabetes Mellitus, which was the second highest risk factor associated with various subtypes, of them, LAA, CE, SVO, SODE and SUDE were being observed 38 (45.24\%), 3 (21.43\%), 32 (50.79\%), 3 (25.00\%) and $22(46.81 \%)(\mathrm{P}=$ 0.000). 89 (40.45\%) patients had Current Smoking Habit which was the third highest risk factor associated with subtypes of ischemic stroke, of them LAA, CE, SVO, SODE and SUDE were being observed 55 (65.47\%), 11 (78.57\%), 14 (22.22\%), 
Table 2. Overall prevalence of subtypes of ischemic strokes $(n=220)$.

\begin{tabular}{lccc}
\hline \multicolumn{1}{c}{ Subtype of ischemic stroke } & N & $\%$ & P-value \\
\hline 1. Large-artery atherosclerosis (LAA) & 84 & 38.18 & 0.01 \\
2. Cardio-embolism (CE) & 14 & 6.36 & 0.000 \\
3. Small-vessel occlusion (SVO) & 63 & 28.64 & 0.000 \\
4. Stroke of other determined etiology (SODE) & 12 & 5.45 & 0.000 \\
5. Stroke of undetermined etiology (SUDE) (3) & 47 & 18.18 & 0.000 \\
\multicolumn{1}{c}{ Total } & 220 & $100 \%$ & \\
\hline
\end{tabular}

Table 3. Descriptive analysis to identify risk factors associated with subtypes of ischemic stroke $(\mathrm{n}=220)$.

\begin{tabular}{lccccccc}
\hline \multicolumn{1}{c}{ Subtypes of stroke } & $\begin{array}{c}\text { LAA } \\
(\mathrm{N} \%)\end{array}$ & $\begin{array}{c}\text { CE } \\
(\mathrm{N} \%)\end{array}$ & $\begin{array}{c}\text { SVO } \\
(\mathrm{N} \%)\end{array}$ & SODE (N\%) & SUDE (N\%) & Total & P-value \\
\hline Risk factors & & & & & & & \\
Hypertension & $61(72.62 \%)$ & $9(64.29 \%)$ & $42(66.67 \%)$ & $4(33.33 \%)$ & $36(76.60 \%)$ & $152(69.09 \%)$ & 0.000 \\
Diabetes Mellitus & $38(45.24 \%)$ & $3(21.43 \%)$ & $32(50.79 \%)$ & $3(25.00 \%)$ & $22(46.81 \%)$ & $98(44.55 \%)$ & 0.000 \\
Smoking history & $55(65.47 \%)$ & $11(78.57 \%)$ & $14(22.22 \%)$ & $5(41.66 \%)$ & $4(8.51 \%)$ & $89(40.45 \%)$ & 0.000 \\
Dyslipidemia & $45(53.57 \%)$ & $00 \%$ & $26(41.27 \%)$ & $00 \%$ & $16(34.04 \%)$ & $87(39.55 \%)$ & 0.000 \\
Heart disease & 00 & $8(57.14 \%)$ & 00 & 00 & 00 & $8(3.64 \%)$ & 0.016 \\
H/O Previous Stroke & $20(23.81 \%)$ & $3(21.43 \%)$ & $4(6.35 \%)$ & $5(41.67 \%)$ & $9(19.15 \%)$ & $41(18.64 \%)$ & 0.000 \\
Positive Familial History & $09(10.71 \%)$ & $1(7.14 \%)$ & $6(9.52 \%)$ & $1(8.33 \%)$ & $8(17.02 \%)$ & $25(11.36 \%)$ & 0.000 \\
Coronary Artery Disease & $11(13.10 \%)$ & $5(35.71 \%)$ & $10(15.87 \%)$ & $1(8.33 \%)$ & $6(12.77 \%)$ & $33(15.00 \%)$ & 0.000 \\
Alcohol Consumption & $35(41.66 \%)$ & $7(50 \%)$ & $3(4.76 \%)$ & $1(8.33 \%)$ & $1(2.12 \%)$ & $47(21.36 \%)$ & 0.023 \\
\hline
\end{tabular}

$5(41.66 \%)$ and $4(8.51 \%)(\mathrm{p}=0.000) .87(39.55 \%$ patients had Dyslipidemia which was significantly associated factor with the subtypes, LAA, 45 (53.57\%), SVO, $26(41.27 \%)$ and SUDE, $16(34.04 \%)(\mathrm{p}=0.000) .8(3.64 \%)$ stroke patients had Heart diseases which was also associated with the prevalence of subtypes $\mathrm{CE}$, 8 (57.14\%) and SUDE, 8 (3.64\%) $(\mathrm{P}=0.010) .41$ (18.64\%) patients had H/O Previous Stroke which was further observed associated factor with the prevalence of subtypes of ischemic stroke, LAA, 20 (23.81\%), CE, 3 (21.43\%), SVO, 4 (6.35\%), SODE, $5(41.67 \%)$ and SUDE, $9(19.15 \%)(\mathrm{p}=0.000) .25(11.36 \%)$ patients had Positive Family History which was associated with the prevalence of subtypes LAA, 09 (10.71\%), CE, 1 (7.14\%), SVO, 6 (9.52\%), SODE, 1 (8.33\%) and SUDE, $8(17.02 \%)(\mathrm{P}=0.000) .33(15.00 \%)$ patients had Coronary Artery Disease which was associated with the prevalence of subtypes LAA, 11 (13.10\%), CE, 5 (35.71\%), SVO, $10(15.87 \%)$, SODE, $1(8.33 \%)$ and SUDE, $6(12.77 \%)(\mathrm{p}=0.000) .47$ (21.36\%) patients had the habit of Alcohol Consumption which was observed associated factor with the prevalence of subtypes of ischemic stroke LAA, 35 (41.66\%), CE, 7 (50\%), SVO, 3 (4.76\%), SODE, 1 (8.33\%) and SUDE, 1 (2.12\%) $(\mathrm{p}=0.023)$.

Table 4 shows the multinomial logistic regression of clinical and demographic 
Table 4. Multinomial logistic regression of clinical and demographic risk factors associated with subtypes $(n=220)$.

\begin{tabular}{|c|c|c|c|c|c|c|c|c|}
\hline \multirow{2}{*}{$\begin{array}{c}\text { Subtypes } \\
\text { Risk Factors }\end{array}$} & \multicolumn{2}{|l|}{ LAA } & \multicolumn{2}{|l|}{$\mathrm{CE}$} & \multicolumn{2}{|l|}{ SVO } & \multicolumn{2}{|l|}{ SUDE } \\
\hline & $\begin{array}{c}\text { AOR } \\
(95 \% \mathrm{CI})\end{array}$ & P-value & $\begin{array}{c}\text { AOR } \\
(95 \% \mathrm{CI})\end{array}$ & $P$-value & $\begin{array}{c}\text { AOR } \\
(95 \% \mathrm{CI})\end{array}$ & $\mathrm{P}$-value & $\begin{array}{c}\text { AOR } \\
(95 \% \mathrm{CI})\end{array}$ & $\mathrm{P}$-value \\
\hline Age & $\begin{array}{c}1.03 \\
(0.983-0.983)\end{array}$ & 0.199 & $\begin{array}{c}0.99 \\
(0.940-1.062)\end{array}$ & 0.971 & $\begin{array}{c}0.99 \\
(0.946-1.046)\end{array}$ & 0.783 & $\begin{array}{c}0.99 \\
(0.947-1.046)\end{array}$ & 0.853 \\
\hline Sex & $\begin{array}{c}1.87 \\
(0.004-855.413)\end{array}$ & 0.841 & $\begin{array}{c}0.04 \\
(2.922-76.659)\end{array}$ & 0.419 & $\begin{array}{c}31.10 \\
(086-0.669)\end{array}$ & 0.253 & $\begin{array}{c}0.14 \\
(0.000-53.801)\end{array}$ & 0.521 \\
\hline Religion & $\begin{array}{c}0.59 \\
(0.000-2.111)\end{array}$ & 0.988 & $\begin{array}{c}0.30 \\
(0.300-0.400)\end{array}$ & 0.000 & $\begin{array}{c}0.55 \\
(0.000-2.111)\end{array}$ & 0.989 & $\begin{array}{c}0.70 \\
(0.000-2.111)\end{array}$ & 0.989 \\
\hline Residence & $\begin{array}{c}4.79 \\
(0.018-1303.551)\end{array}$ & 0.584 & $\begin{array}{c}0.97 \\
(0.001-0.664)\end{array}$ & 0.994 & $\begin{array}{c}0.22 \\
(0.001-45.753)\end{array}$ & 0.583 & $\begin{array}{c}0 . .41 \\
(0.002-107.317)\end{array}$ & 0.754 \\
\hline Hypertension & $\begin{array}{c}3.96 \\
(0.47-33.06)\end{array}$ & 0.020 & $\begin{array}{c}15.81 \\
(1.533-163.113)\end{array}$ & 0.020 & $\begin{array}{c}3.81 \\
(.449-32.397)\end{array}$ & 0.220 & $\begin{array}{c}3.97 \\
(0.457-34.498)\end{array}$ & 0.211 \\
\hline Diabetes Mellitus & $\begin{array}{c}2.7 .4 \\
(0.74-9.97)\end{array}$ & 0.128 & $\begin{array}{c}0.69 \\
(0.130-3.759)\end{array}$ & 0.675 & $\begin{array}{c}2.75 \\
(0.736-10.303)\end{array}$ & 0.132 & $\begin{array}{c}2.08 \\
(0.541-34.498)\end{array}$ & 0.286 \\
\hline Dyslipidemia & $\begin{array}{c}0.14 \\
(0.018-1.179)\end{array}$ & 0.071 & $\begin{array}{c}0.04 \\
(0.004-0.475)\end{array}$ & 0.010 & $\begin{array}{c}0.15 \\
(0.019-1.306)\end{array}$ & 0.087 & $\begin{array}{c}0.15 \\
(0.018-1.275)\end{array}$ & .082 \\
\hline Heart Diseases & $\begin{array}{c}4.90 \\
(0.282-85.052)\end{array}$ & 0.275 & $\begin{array}{c}0.40 \\
(.0 .020-8.071)\end{array}$ & 0.550 & $\begin{array}{c}0.90 \\
(0.090-8.982)\end{array}$ & 0.928 & $\begin{array}{c}1.35 \\
(0.110-16.574)\end{array}$ & 0.815 \\
\hline $\begin{array}{l}\text { Positive Familial } \\
\text { History }\end{array}$ & $\begin{array}{c}2.40 \\
(5.91-9.86)\end{array}$ & 0.000 & $\begin{array}{c}0.96 \\
(0.967-0.967)\end{array}$ & 0.590 & $\begin{array}{c}2.85 \\
(1.059-7.71)\end{array}$ & 0.000 & $\begin{array}{c}5.06 \\
(5.060-6.060)\end{array}$ & 0.000 \\
\hline $\begin{array}{l}\text { Coronary Artery } \\
\text { Disease }\end{array}$ & $\begin{array}{c}1.00 \\
(0.198-5.099)\end{array}$ & 0.995 & $\begin{array}{c}0.96 \\
(0967-0967)\end{array}$ & 0.590 & $\begin{array}{c}1.09 \\
(0.203-5.956)\end{array}$ & 0.913 & $\begin{array}{c}1.71 \\
(0.287-10.293)\end{array}$ & 0.553 \\
\hline $\begin{array}{l}\text { Alcohol } \\
\text { Consumption }\end{array}$ & $\begin{array}{c}1.17 \\
(0.324-4.293)\end{array}$ & 0.803 & $\begin{array}{c}2.99 \\
(0.435-20.594)\end{array}$ & 0.265 & $\begin{array}{c}2.99 \\
(0.738-12.160)\end{array}$ & 0.234 & $\begin{array}{c}2.43 \\
(0.563-10.478)\end{array}$ & 0.234 \\
\hline $\begin{array}{l}\text { H/O Previous } \\
\text { Stroke }\end{array}$ & $\begin{array}{c}4.95 \\
(1.170-2.100)\end{array}$ & 0.000 & $\begin{array}{c}2.45 \\
(2.458-2.458)\end{array}$ & 0.000 & $\begin{array}{c}3.17 \\
(7.564-1.328)\end{array}$ & 0.000 & $\begin{array}{c}1.08 \\
(2.648-9-4.405)\end{array}$ & 0.001 \\
\hline Smoking History & $\begin{array}{c}1.58 \\
(2.531-1.114)\end{array}$ & 0.000 & $\begin{array}{c}0.85 \\
(0.000)\end{array}$ & 1.000 & $\begin{array}{c}9.31 \\
(8.457-3.505)\end{array}$ & 0.000 & $\begin{array}{c}7.73 \\
(7.734-8.734)\end{array}$ & 0.001 \\
\hline
\end{tabular}

a. The reference category is: SODE.

risk factors associated with subtypes of ischemic stroke. According to multinomial logistic regression, the clinical and demographic factors associated with the prevalence of subtypes of ischemic stroke were Age, [LAA $(\mathrm{AOR}=1.03)(\mathrm{P}=$ 0.199), $\mathrm{CE}(\mathrm{AOR}=0.99)(\mathrm{P}=0.971), \mathrm{SOV}(\mathrm{AOR}=0.99)(\mathrm{P}=0.783), \mathrm{SUDE}$ $(\mathrm{AOR}=0.99)(\mathrm{P}=0.853)]$, Sex [LAA $(\mathrm{AOR}=1.87)(\mathrm{P}=0.841), \mathrm{CE}(\mathrm{AOR}=$ $0.04)(\mathrm{P}=0.419), \mathrm{SOV}(\mathrm{AOR}=1.10)(\mathrm{P}=0.253), \mathrm{SUDE}(\mathrm{AOR}=0.14)(\mathrm{P}=$ $0.521)$ ], Religion [LAA $(\mathrm{AOR}=0.59)(\mathrm{P}=0.988), \mathrm{CE}(\mathrm{AOR}=0.30)(\mathrm{P}=0.000)$, SOV $(A O R=0.55)(P=0.989)$, SUDE $(A O R=0.70)(P=0.989)]$, Residence [LAA $(\mathrm{AOR}=4.79)(\mathrm{P}=0.584), \mathrm{CE}(\mathrm{AOR}=0.97)(\mathrm{P}=0.994), \mathrm{SOV}(\mathrm{AOR}=$ 0.22) $(\mathrm{P}=0.583)$, SUDE $(\mathrm{AOR}=0.41)(\mathrm{P}=0.754)$ ], Hypertension [LAA $(\mathrm{AOR}=$ 
3.96) $(\mathrm{P}=0.020), \mathrm{CE}(\mathrm{AOR}=5.83)(\mathrm{P}=0.020), \mathrm{SOV}(\mathrm{AOR}=0.3 .81)(\mathrm{P}=$ 0.220), SUDE $(A O R=3.97)(P=0.211)$, Diabetes Mellitus $[\mathrm{LAA}(\mathrm{AOR}=2.74)$ $(\mathrm{P}=0.128), \mathrm{CE}(\mathrm{AOR}=0.69)(\mathrm{P}=0.675), \mathrm{SOV}(\mathrm{AOR}=2.75)(\mathrm{P}=0.132), \mathrm{SUDE}$ $(\mathrm{AOR}=2.08)(\mathrm{P}=0.256)]$, Dyslipidemia $[\mathrm{LAA}(\mathrm{AOR}=0.14)(\mathrm{P}=0.071), \mathrm{CE}$ $(A O R=0.04)(P=0.010), \operatorname{SOV}(A O R=0.15)(P=0.087), \operatorname{SUDE}(A O R=0.15)$ $(\mathrm{P}=0.82)$ ], Heart Diseases [LAA $(\mathrm{AOR}=4.90)(\mathrm{P}=0.275), \mathrm{CE}(\mathrm{AOR}=0.40)(\mathrm{P}$ $=0.550), \operatorname{SOV}(\mathrm{AOR}=0.90)(\mathrm{P}=0.928), \operatorname{SUDE}(\mathrm{AOR}=1.35)(\mathrm{P}=0.815)]$, Positive Family History [LAA $(\mathrm{AOR}=2.40)(\mathrm{P}=0.000), \mathrm{CE}(\mathrm{AOR}=0.96)(\mathrm{P}=$ $0.590)$, SOV $(A O R=2.85)(P=0.000), \operatorname{SUDE}(A O R=5.06)(P=0.000)]$, Positive Family History [LAA $(\mathrm{AOR}=2.40)(\mathrm{P}=0.000), \mathrm{CE}(\mathrm{AOR}=0.96)(\mathrm{P}=$ $0.590)$, SOV $(A O R=2.85)(P=0.000)$, SUDE $(A O R=5.06)(P=0.000)]$, Coronary Artery Diseases [LAA $(\mathrm{AOR}=1.00)(\mathrm{P}=0.995), \mathrm{CE}(\mathrm{AOR}=0.96)(\mathrm{P}=$ 0.590), SOV $(A O R=1.09)(P=0.913)$, SUDE $(A O R=1.71)(P=0.553)]$, Alcohol Consumption [LAA $(\mathrm{AOR}=1.17)(\mathrm{P}=0.803), \mathrm{CE}(\mathrm{AOR}=2.99)(\mathrm{P}=0.265)$, SOV $(A O R=2.99)(P=0.234), \operatorname{SUDE}(A O R=2.43)(\mathrm{P}=0.234)], \mathrm{H} / \mathrm{O}$ Previous Stroke $[\mathrm{LAA}(\mathrm{AOR}=4.95)(\mathrm{P}=0.000), \mathrm{CE}(\mathrm{AOR}=2.45)(\mathrm{P}=0.000), \mathrm{SOV}$ $(\mathrm{AOR}=3.17)(\mathrm{P}=0.000), \operatorname{SUDE}(\mathrm{AOR}=1.08)(\mathrm{P}=0.000)]$, Smoking History [LAA $(\mathrm{AOR}=1.58)(\mathrm{P}=0.000), \mathrm{CE}(\mathrm{AOR}=0.85)(\mathrm{P}=1.000), \mathrm{SOV}(\mathrm{AOR}=$ 9.31) $(\mathrm{P}=0.000)$, SUDE $(\mathrm{AOR}=7.73)(\mathrm{P}=0.000)$.

\section{Discussion}

The risk of stroke increased in the developing countries of the world in the last decade [20]. Some studies in India reported stroke is increasing in an alarming way in India. Around 1.54 million Indians are affected by strokes every year and the worse is 90 percent of stroke patients failed to reach hospital on time [21]. A recent prevalence-based study in Pakistan reported, the highest prevalence of stroke in the world in Pakistan due to the varieties of risk factors [22]. However, the present study aimed to investigate the risks factors associated with the subtypes of ischemic stroke in Bangladesh context and included a total of 220 confirm ischemic stroke patients by MRI/CT SCAN. In this current study, among the age groups of the patients above 30 years, the highest prevalence of subtypes of ischemic stroke was observed in $(51-60)$ years which was $70(31.82 \%)$ of them LAA was the highest $36(16.36 \%)$. A slightly higher male predominance was observed in the study. They found ischemic stroke among the $>70$ years age group had a high risk to stroke [23]. In our study, among the studied patients, male was $150(68.18 \%)$, whereas female was $70(31.82 \%)$ and we observed the proportion of male was greater than the female. In this study, among the studied stroke patients, the total subtypes of ischemic stroke, LAA, CE, SVO, SODE and SUDE were being observed, 84 (38.18\%), 14 (6.36\%), 63 (28.64\%), 12 (5.45\%) and $47(18.18 \%)$. But in an Indian Study found the total subtypes of ischemic stroke patients, LAA (41\%), CE (18\%), SVO (10\%), SODE (4\%), and SUDE (27\%) respectively which differed with the findings of our study to some extent [24]. Eighty-nine (40.45\%) patients had Current Smoking Habit which was the 
third highest risk factor associated with subtypes of ischemic stroke, of them LAA, CE, SVO, SODE and SUDE were being observed 55 (65.47\%), 11 (78.57\%), $14(22.22 \%), 5(41.66 \%)$ and 4 (8.51\%). Thirty-nine-point fifty five percent (39.55\%) patients had Dyslipidemia which was significantly associated factor with the subtypes, LAA, 45 (53.57\%), SVO, 26 (41.27\%) and SUDE, 16 (34.04\%). Eight (3.64\%) stroke patients had heart diseases which was also associated with the prevalence of subtypes CE, 8 (57.14\%) and SUDE, 8 (3.64\%). The similar male-female ratio difference was also observed in another Indian study. In that study, they observed $54 \%$ were male and $46 \%$ were female [25]. So, we can say that the male suffered more from subtypes of ischemic stroke for having such unfortunate habits and diseases (hypertension, smoking, coronary artery disease, dyslipidemia, etc.) in a higher rate than the female [26] [27]. Concluded insignificant association between gender and ischemic stroke subtypes in their studies conducted in China and Japan respectively [28] [29]. So, there may have life leading impact on the incidence of subtypes of ischemic stroke among the people in different countries. In a study it was observed, $57.6 \%$ of patients had a history of hypertension, $23 \%$ had diabetes, and $44.6 \%$ had a history of smoking [30]. In our study, we observed in LAA. Hypertension, Diabetes, Smoking history and Dyslipidemia were the major common risk factors. The multinomial logistic regression of clinical and demographic risk factors associated with subtypes of ischemic stroke. According to multinomial logistic regression, the clinical and demographic factors associated with the prevalence of subtypes of ischemic stroke were Age, LAA (AOR = 1.03), Sex LAA (AOR = 1.87), Religion LAA $($ AOR $=0.59)$, Residence LAA $(A O R=4.79)$, Hypertension LAA $(A O R=$ 3.96), Diabetes Mellitus LAA (AOR = 2.74), Dyslipidemia LAA (AOR = 0.14), Heart Diseases LAA (AOR = 4.90), Positive Family History LAA (AOR = 2.40), Positive Family History LAA $(\mathrm{AOR}=2.40)$, Coronary Artery Diseases LAA $(\mathrm{AOR}=1.00)$, Alcohol Consumption LAA $(\mathrm{AOR}=1.17)$, Previous Stroke LAA $(\mathrm{AOR}=4.95), \mathrm{CE}(\mathrm{AOR}=2.45), \mathrm{SOV}(\mathrm{AOR}=3.17), \operatorname{SUDE}(\mathrm{AOR}=1.08)$, Smoking History LAA (AOR = 1.58), In their study, they observed Hypertension and diabetes were the major common risk factors associated with the LAA [31]. According to Pakistan Stroke Society, however, more than $70 \%$ of patients with stroke are hypertensive [32]. Almost the similar observation was found in our present study (69.09\%) hypertensive patients. Another study conducted in Indonesia in LAA subtype, they observed, the most common risk factor was hypertension in $85.3 \%(\mathrm{n}=118)$ of patients while diabetes mellitus as the second major risk factor in 77 (55\%) patients [33]. In our study, through multinomial logistic regression, we observed, the association between risk factors and the prevalence of subtypes comparably responsible for the prevalence of subtypes.

\section{Limitations of the Study}

This was a single center prospective study with small sample size. So, the study results may not reflect the exact scenario of the whole country. 


\section{Conclusion}

This study prevails the people of Bangladesh are vulnerable to various subtypes of ischemic stroke. The higher prevalence of Large-artery atherosclerosis (LAA) in our patients suggests the presence of uncontrolled hypertension, diabetes mellitus, smoking habit and dyslipidemia So, importance should be given to various subtypes of ischemic stroke and collective preventive measures and strategies are to be taken to control the associated risk factors especially hypertension, diabetes mellitus, smoking habit and dyslipidemia to decrease the stroke mortality rate in Bangladesh.

\section{Recommendations}

Multi centered study is recommended with a large sample size and long duration which may prevail the stroke status of the whole Bangladesh. Importance should be given to various subtypes of ischemic stroke and collective preventive measures and strategies are to be taken to control the associated risk factors especially hypertension, diabetes mellitus, smoking habit and dyslipidemia to decrease the stroke mortality rate in Bangladesh.

\section{Conflicts of Interest}

The authors declare no conflicts of interest regarding the publication of this paper.

\section{References}

[1] Yazdanyar, A. and Newman, A.B. (2009) The Burden of Cardiovascular Disease in the Elderly: Morbidity, Mortality, and Costs. Clinics in Geriatric Medicine, 25, 563-577. https://doi.org/10.1016/j.cger.2009.07.007

[2] World Health Organization (2010) World Health Report 2000. Health Systems: Improving Performance. WHO, Geneva.

[3] Foulkes, M.A., Wolf, P.A., Price, T.R., Mohr, J.P. and Hier, D.B. (1988) The Stroke Data Bank: Design, Methods, and Baseline Characteristics. Stroke, 19, 547-554.

https://doi.org/10.1161/01.STR.19.5.547

[4] Feigin, V.L., Forouzanfar, M.H., Krishnamurthi, R., Mensah, G.A., Connor, M., Bennett, D.A., et al. (2014) Global and Regional Burden of Stroke during 1990-2010: Findings from the Global Burden of Disease Study 2010. The Lancet, 383, 245-255. https://doi.org/10.1016/S0140-6736(13)61953-4

[5] Das, S.K., Banerjee, T.K., Biswas, A., Roy, T., Raut, D.K., Mukherjee, C.S., et al. (2007) A Prospective Community-Based Study of Stroke in Kolkata, India. Stroke, 38, 906-910. https://doi.org/10.1161/01.STR.0000258111.00319.58

[6] Islam, M.N., Moniruzzaman, M., Khalil, M.I., Basri, R., Alam, M.K., Loo, K.W. and Gan, S.H. (2013) Burden of Stroke in Bangladesh. International Journal of Stroke, 8 , 211-213. https://doi.org/10.1111/j.1747-4949.2012.00885.x

[7] Mohammad, Q.D., Habib, M., Hoque, A., Alam, B., Haque, B., Hossain, S., et al. (2011) Prevalence of Stroke above Forty Years. MMJ, 20, 640-644.

[8] Aho, K., Harmsen, P., Hatano, S., Marquardsen, J., Smirnov, V.E. and Strasser, T. (1980) Cerebrovascular Disease in the Community: Results of a WHO Collaborative 
Study. Bulletin of the World Health Organization, 58, 113.

[9] Sacco, R.L., Kasner, S.E., Broderick, J.P., Caplan, L.R., Connors, J.J. and Culebras, A. (2013) An Updated Definition of Stroke for the 21st Century: A Statement for Healthcare Professionals from the American Heart Association/American Stroke Association. Stroke, 44, 2064-2089. https://doi.org/10.1161/STR.0b013e318296aeca

[10] Dávalos, A. (2005) Thrombolysis in Acute Ischemic Stroke: Successes, Failures, and New Hopes. Cerebrovascular Diseases, 20, 135-139. https://doi.org/10.1159/000089367

[11] O’Donnell, M.J., Xavier, D., Liu, L., Zhang, H., Chin, S.L. and Rao-Melacini, P. (2010) Risk Factors for Ischaemic and Intracerebral Haemorrhagic Stroke in 22 Countries (the INTERSTROKE Study): A Case-Control Study. The Lancet, 376, 112-123. https://doi.org/10.1016/S0140-6736(10)60834-3

[12] Renjen, P.N., Beg, M.A. and Ahmad, K. (2015) Epidemiological Study of Incidence and Risk Factors of Ischemic Stroke Subtypes According to Trial of ORG 10172 in Acute Stroke Treatment Criteria: A 3 Years, Hospital-Based Study. International Journal of Medicine and Public Health, 5, 50-54. https://doi.org/10.4103/2230-8598.151258

[13] Hu, G., Sarti, C., Jousilahti, P., Peltonen, M., Qiao, Q., Antikainen, R. and Tuomilehto, J. (2005) The Impact of History of Hypertension and Type 2 Diabetes at Baseline on the Incidence of Stroke and Stroke Mortality. Stroke, 36, 2538-2543. https://doi.org/10.1161/01.STR.0000190894.30964.75

[14] Bamford, J., Sandercock, P., Dennis, M., Warlow, C. and Burn, J. (1991) Classification and Natural History of Clinically Identifiable Subtypes of Cerebral Infarction. The Lancet, 337, 1521-1526. https://doi.org/10.1016/0140-6736(91)93206-O

[15] Sacco, S.E., Whisnant, J.P., Broderick, J.P., Phillips, S.J. and O'Fallon, W.M. (1991) Epidemiological Characteristics of Lacunar Infarcts in a Population. Stroke, 22, 1236-1241. https://doi.org/10.1161/01.STR.22.10.1236

[16] Sage, J.I. and Van Uitert, R.L. (1983) Risk of Recurrent Stroke in Patients with Atrial Fibrillation and Non-Valvular Heart Disease. Stroke, 14, 537-540. https://doi.org/10.1161/01.STR.14.4.537

[17] Gent, M., Easton, J.D., Hachinski, V., Panak, E., Sicurella, J., Blakely, J., et al. (1989) The Canadian American Ticlopidine Study (CATS) in Thromboembolic Stroke. The Lancet, 333, 1215-1220. https://doi.org/10.1016/S0140-6736(89)92327-1

[18] Marsh, E.E., Adams, H.P., Biller, J., Wasek, P., Banwart, K., Mitchell, V. and Woolson, R. (1989) Use of Antithrombotic Drugs in the Treatment of Acute Ischemic Stroke A Survey of Neurologists in Practice in the United States. Neurology, 39, 1631-1631. https://doi.org/10.1212/WNL.39.12.1631

[19] Muir, K.W. (2002) Heterogeneity of Stroke Pathophysiology and Neuroprotective Clinical Trial Design. Stroke, 33, 1545-1550. https://doi.org/10.1161/01.STR.0000018684.86293.AB

[20] Feigin, V.L., Lawes, C.M., Bennett, D.A., Barker-Collo, S.L. and Parag, V. (2009) Worldwide Stroke Incidence and Early Case Fatality Reported in 56 Population-Based Studies: A Systematic Review. The Lancet Neurology, 8, 355-369. https://doi.org/10.1016/S1474-4422(09)70025-0

[21] Dutt, S. (2019) Every 20 Seconds, 1 Indian Suffers a Brain-Stroke. Mumbai. Tribune.

[22] Kamal, A., Itrat, A., Murtaza, M., Khan, M., Rasheed, A., Ali, A., et al. (2009) The Burden of Stroke and Transient Ischemic Attack in Pakistan: A Community-Based Prevalence Study. BMC Neurology, 9, 58. https://doi.org/10.1186/1471-2377-9-58 
[23] Bogousslavsky, J., Van Melle, G. and Regli, F. (1988) The Lausanne Stroke Registry: Analysis of 1,000 Consecutive Patients with First Stroke. Stroke, 19, 1083-1092. https://doi.org/10.1161/01.STR.19.9.1083

[24] Kaul, S., Sunitha, P., Suverna, A., Meena, A.K., Uma, M. and Reddy, J.M. (2002) Subtypes of Ischemic Stroke in a Metropolitan City of South India (One Year Data from Hospital Based Stroke Registry). Neurology India, 50, S8-S14.

[25] Feroz, M.T., Ali, L.M., Sheikh, M., Raque, A. and Rind, S.M. (2016) SocioDemographic Risk Factors for Hemorrhagic and Ischemic Stroke: A Study in Tertiary Care Hospital of Hyderabad. Journal of the College of Physicians and Surgeons Pakistan, 11, 6.

[26] Palm, F., Urbanek, C., Wolf, J., et al. (2012) Etiology, Risk Factors and Sex Differences in Ischemic Stroke in the Ludwigshafen Stroke Study, a Population-Based Stroke Registry. Cerebrovascular Diseases, 33, 69-75.

https://doi.org/10.1159/000333417

[27] Martin-Schild, S. and Samai, A. (2015) Sex Differences in Predictors of Ischemic Stroke: Current Perspectives. Vascular Health and Risk Management, 11, 427-436. https://doi.org/10.2147/VHRM.S65886

[28] Yu, C., An, Z., Zhao, W., Wang, W., Gao, C., Liu, S., et al. (2015) Sex Differences in Stroke Subtypes, Severity, Risk Factors, and Outcomes among Elderly Patients with Acute Ischemic Stroke. Frontiers in Aging Neuroscience, 7, 174. https://doi.org/10.3389/fnagi.2015.00174

[29] Turin, T.C., Kita, Y., Rumana, N., Nakamura, Y., Takashima, N., Ichikawa, M., et al. (2010) Ischemic Stroke Subtypes in a Japanese Population: Takashima Stroke Registry 1988-2004. Stroke, 41, 1871-1876. https://doi.org/10.1161/STROKEAHA.110.581033

[30] Mohammad, Q.D., Habib, M., Mondal, B.A., Chowdhury, R.N., Hasan, M.H., Haque, M.A., et al. (2014) Stroke in Bangladeshi Patients and Risk Factor. MMJ, 23, 520-529.

[31] Jackson, A.C., Hutchison, A., Dennis, S.M., Wardlaw, M.J., Lindgren, A., Norrving, B., et al. (2010) Differing Risk Factor Profiles of Ischemic Stroke Subtypes: Evidence for a Distinct Lacunar Arteriopathy? Stroke, 41, 624-629. https://doi.org/10.1161/STROKEAHA.109.558809

[32] Aquil, N., Begum, I., Ahmed, A., Vohra, E.A. and Soomro, B.A. (2011) Risk Factors in Various Subtypes of Ischemic Stroke According to TOAST Criteria. Journal of College of Physicians and Surgeons Pakistan, 21, 280-283.

[33] Harris, S., Sungkar, S., Rasyid, A., Kurniawan, M., Mesiano, T. and Hidayat, R. (2018) TOAST Subtypes of Ischemic Stroke and Its Risk Factors: A Hospital-Based Study at Cipto Mangunkusumo Hospital, Indonesia. Stroke Research and Treatment, 2018, Article ID: 9589831. https://doi.org/10.1155/2018/9589831 